\title{
Índice de vulnerabilidade como garantia de acesso aos benefícios do Programa Família Paranaense
}

\section{Vulnerability index as a guarantee of access to the benefits of the Paranaense Family Programme}

\author{
Cristiane Gonçalves de Souza* \\ Jussara Ayres Bourguignon**
}

\begin{abstract}
Resumo: Vulnerabilidade social é uma categoria teórica polissêmica que aponta para muitas possibilidades de reflexão e mensuração em contextos que revelam as condições em que vivem famílias usuárias da política pública de Assistência Social. No Estado do Paraná, o governo estabeleceu, desde o ano de 2012, o Programa Família Paranaense como estratégia para promoção da proteção social às famílias em situação de vulnerabilidade social. O Programa propõe ações planejadas e de caráter intersetorial, articulando as políticas de saúde, educação, habitação, agricultura e trabalho, bem como objetiva consolidar uma rede integrada de proteção às famílias cadastradas. Diante disso, este artigo tem por objetivo demonstrar a relevância do Índice de Vulnerabilidade das Famílias do Paraná, enquanto estratégia para acesso do usuário ao Programa Família Paranaense e aos seus benefícios. Para tanto, pautou-se em pesquisa bibliográfica e documental, utilizando principalmente informações disponibilizadas pelo Governo do Estado do Paraná e pelo Sistema de Acompanhamento do Programa Família Paranaense. O artigo é de natureza descritiva e foi organizado de forma a evidenciar a categoria vulnerabilidade social e sua relação com o programa Família Paranaense, tal como a configuração do Índice de Vulnerabilidade das Famílias do Paraná, nos aspectos que expressam as condições concretas em que vivem as famílias participantes do programa no Município de Ponta Grossa/Pr. Por fim, conclui-se que os indicadores são potenciais instrumentos de monitoramento e avaliação das políticas sociais e podem apontar estratégias de natureza intersetorial para o enfrentamento das demandas concretas apresentadas pelos usuários da política de Assistência Social local.
\end{abstract}

Palavras-Chave: Política Pública, Vulnerabilidade Social, Família, Indicadores Sociais

\footnotetext{
* Doutora em Ciências Sociais Aplicadas (UEPG, 2017), mestre em em Ciências Sociais Aplicadas (UEPG, 2011), Especialista em Gestão Pública (UAB, 2011), Bacharel em Serviço Social (UEPG, 2008). Pós-doutoranda no Programa de Pós-graduação em Serviço Social e Política Social da UEL. Diretora de Ações Afirmativas e Diversidade da PRAE-UEPG. E-mail: souzacgj@ gmail.com.

${ }^{* *}$ Doutora em Serviço Social (PUC/SP, 2005), Mestre em Prática Profissional e Política Social ( PUC/SP, 1997), Especialista em Política Social (UEPG,1994) . Professora Associada junto ao Programa de Pós-Graduação em Ciências Sociais Aplicadas e ao Departamento de Serviço Social da Universidade Estadual de Ponta Grossa/PR. E-mail. juaybo@gmail.com.
} 


\begin{abstract}
Social vulnerability is a polysemic theoretical category that points to many possibilities for reflection and measurement in contexts that reveal the conditions in which families that use public social assistance policies live. In the State of Paraná, the government established the Paranaense Family Programme since 2012, as a strategy to promote social protection to families in socially vulnerable situations. The Program proposes planned and intersectoral actions, articulating health, education, housing, farming and work policies and aims to consolidate an integrated protection network for registered families. That said, this article aims to demonstrate the relevance of the Vulnerability Index of Families in Paraná as a strategy for user access to the Paranaense Family Programme and its benefits. It was based on bibliographic and documentary research using mainly information provided by the government of the State of Paraná and the Paranaense Family Programme Monitoring System. The article of descriptive character was organised so as to highlight the category social vulnerability and its relationship with the Família Paranaense Programme and according to the configuration of the Index of Vulnerability of Families of Paraná in aspects that express the concrete conditions in which families participating in the programme live in the municipality of Ponta Grossa/PR. Lastly, It is concluded that the indicators are potential instruments for monitoring and evaluating social policies and can point out strategies of an intersectoral character to face the concrete demands presented by the users of the Social Assistance policy in the local reality.
\end{abstract}

Key words: Public Policy, Social Vulnerability, Family, Social Indicators.

Recebido em 31/08/2021. Aceito em: 31/08/2020

\title{
Introdução
}

A temática do acompanhamento de famílias em situação de vulnerabilidade social é uma constante no interior das políticas sociais no Brasil, haja vista que muitas políticas sociais indicam a necessidade de implementar estratégias capazes de realizar um acompanhamento, com desenvolvimento de plano de ação, com o intuito de contribuir para o enfrentamento da situação de vulnerabilidade social. Exemplo disso é a Política de Assistência Social, que tem como centro de atenção famílias que estão em situação de vulnerabilidade e risco social.

Cabe pontuar que a vulnerabilidade é uma categoria teórica polissêmica, ou seja, a depender do texto/autor(a) de referência pode apresentar diversas conotações. Vulnerabilidade social também é uma categoria multifacetada, pois ao considerá-la, várias são as determinações sociais que se relacionam para avaliar se uma família está ou não em situação de vulnerabilidade social.

Acerca das determinações sociais e determinantes sociais, é oportuno sublinhar que a primeira tem articulação com a temática da desigualdade social, já que exige ponderar sobre as 
disparidades sociais existentes no processo de acesso ao trabalho e renda, que remete a considerar as condições materiais e objetivas de vida do sujeito.

Garbois et al (2017) explicam que numa perspectiva crítica, isto é, marxista, ao se considerar as condições materiais, a categoria trabalho e as relações de produção e reprodução da vida social emergem como chave de leitura para compreender o processo de determinação social. Sob essa perspectiva, a determinação social da pobreza, por exemplo, relaciona-se com a condição de vida do sujeito, que é condicionada pelo lugar que ocupa nas relações sociais e econômicas. Ou seja, lugar que ocupa na divisão social do trabalho e as implicações sociais que isso gera sobre o fenômeno da pobreza.

Por sua vez, Garbois et al (2017) expõem que os determinantes sociais, por vezes, são relacionados à ideia de fatos sociais, haja vista que num primeiro momento é considerado o comportamento do sujeito de forma isolada. Como consequência, tal comportamento incide na condição de pobreza e, portanto, na coesão social. Nessa lógica de análise está presente a perspectiva positivista de Durkheim.

[...] uma revisitação às obras de Durkheim, deixa claro os pressupostos positivistas presentes na ideia de determinantes sociais[...], na medida em que desvela os argumentos filosóficos de fragmentação e esquematização dos fenômenos sociais em fatores diversos, passíveis de serem estudados isoladamente, como 'fatos sociais'. A consequência de operar dessa maneira reforça a disciplinarização e a divisão do conhecimento em 'setores de saber' incomunicáveis[...]. (GARBOIS et al., 2017, p.73).

Disso posto, neste texto, entende-se que a vulnerabilidade social não é sinônimo de pobreza, visto que se relaciona a diversos elementos que exigem a reflexão sobre acesso ao trabalho e renda, acesso a serviços de saúde, educação, assistência social, acesso à moradia digna, presença de situações de violação de direitos, etc. Contudo, é importante frisar que a maioria das famílias atendidas pela política pública de Assistência Social vivencia a extrema pobreza e privação de condições básicas para manutenção de sua sobrevivência, reforçando que vulnerabilidade social é marcada pela pobreza e esse debate pode ser encontrado em Sposati (2009) e Souza (2018), por exemplo.

Este artigo tem por objetivo demonstrar a relevância do Índice de Vulnerabilidade das Famílias do Paraná, enquanto estratégia para acesso do usuário ao Programa Família Paranaense ${ }^{1}$ e aos seus benefícios. Para tanto, pautou-se em pesquisa bibliográfica e documental. As fontes de ordem documental foram os dados disponibilizados pelo governo do Estado do Paraná e pelo Sistema de Acompanhamento do Programa Família Paranaense, presentes em manuais, informes técnicos, entre outros. As fontes bibliográficas ficaram centradas, prioritariamente, nos seguintes autores: Abramovay et al (2002); Carmo e Guizardi (2018); Gabatz (2015); Monteiro (2011); Nazareno et al (2012); Semzezem e Alves (2013); Silveira (2007); Souza (2018) e Sposati (2009).

O artigo está estruturado em dois tópicos centrais, sendo que o primeiro trata de reflexões sobre a categoria vulnerabilidade social e sua relação com o Programa Família Paranaense. Assim como apresenta a configuração do Índice de Vulnerabilidade das Famílias do Paraná (IVF - PR). O segundo tópico trata do Município de Ponta Grossa, de sua adesão ao programa em questão e

\footnotetext{
${ }^{1}$ O Programa passou por reformulações em relação ao nome, devido à mudança de gestão do governo Estadual, o nome oficial do Programa é "Nossa Gente Paraná", entretanto, neste artigo foi adotado Programa Família Paranaense, pois, em documentos e sites oficiais do governo do Paraná, esse é o nome que continua sendo utilizado no ano de 2021.
} 
dos aspectos que expressam a situação de vulnerabilidade social das famílias participantes do programa.

\section{Vulnerabilidade social: elementos para reflexão}

Monteiro (2011) traz importante reflexão sobre o necessário debate em torno da categoria vulnerabilidade social, enquanto contribui para balizar processos de monitoramento e avaliação de políticas sociais. Para tanto, é preciso considerar múltiplos e complexos fatores decorrentes do contexto social em que as populações se inserem, buscando construir formas de sociabilidade. Nestes contextos, a ausência ou precarização de recursos materiais deve ser considerada, visto que agrava a satisfação de necessidades essenciais à sobrevivência. Mas não só as condições materiais de sobrevivência fazem parte da constituição da vulnerabilidade social, o acesso a recursos simbólicos também pode contribuir para superação da vulnerabilidade social ou a sua ausência pode favorecer o agravamento desta condição. No que se refere à dimensão simbólica, também cabe destacar que questões como raça, gênero e etnia impactam nas condições de vulnerabilidade, ampliando sua compreensão para além da dimensão econômica. Assim, vulnerabilidade social é produto das transformações societárias e afeta profundamente a vida do cidadão e cidadã enquanto usuário das políticas sociais. Isso implica, conforme Monteiro (2011, p.35), em um composto complexo de características e também de “[...] recursos materiais ou simbólicos e de habilidades inerentes a indivíduos ou grupos, que podem ser insuficientes ou inadequados para o aproveitamento das oportunidades disponíveis na sociedade."

Ainda, segundo a mesma autora, na esfera da proteção social não contributiva ${ }^{2}$, a política pública de Assistência Social e os programas decorrentes ocupam papel central em oferecer estratégias de fortalecimento dos sujeitos para que possam acessar recursos materiais e simbólicos e oportunizar meios de mobilidade social, emancipação social e acesso a direitos sociais.

Avançando, as contribuições de Gabatz (2015, p. 42) são oportunas, pois indicam que “[...] as situações de vulnerabilidade são constitutivas de uma sociedade fundada na desigualdade e guiada por uma lógica que reproduz a divisão desproporcional de ativos físicos, pessoais e sociais."

Na perspectiva de Abramovay et al (2002), há uma relação negativa entre as possibilidades de acesso à estrutura social, econômica e cultural regulada e ofertada pelo Estado e os recursos materiais ou simbólicos pertencentes aos indivíduos, grupos e comunidades, gerando situações de fragilidades e debilidades quanto às possibilidades de mobilidade social. Os recursos materiais ou simbólicos, reconhecidos como ativos, são elementos essenciais à configuração das situações

\footnotetext{
${ }^{2}$ Sobre a proteção social não contributiva Sposati (2009, p. 22) informa que "A característica de não contributiva quer dizer que não é exigido pagamento específico para oferecer a atenção de um serviço. [...]. O acesso é custeado pelo financiamento público, cuja receita vem de taxas e impostos. Assim, os custos e o custeio são rateados entre todos os cidadãos. A proteção social não contributiva significa que o acesso aos serviços e benefícios independe de pagamento antecipado ou no ato da atenção."

Sposati (2009, p.42/43) afirma também que "O modelo de proteção social não contributiva é assentado nos princípios de: universalidade - significando que pode ser acessado por todos os cidadãos que dele necessitem, independentemente do território onde vivem, e sob a diretriz ética de ser portador do direito à proteção social. Alçar a universalidade para além do respeito ao princípio ético significa ter capacidade concreta de proporcionar resposta institucional expressa por meio da instalação de infraestrutura de dispositivos de atenção e de qualidade técnica de ação. matricialidade sociofamiliar - parte da concepção de que a família é o núcleo protetivo intergeracional, presente no cotidiano e que opera tanto o circuito de relações afetivas como de acessos materiais e sociais. Fundamenta-se no direito à proteção social das famílias, mas respeitando seu direito à vida privada."
} 
de vulnerabilidade enfrentadas pelos sujeitos, desde que articulados às oportunidades desenvolvidas pelo mercado, Estado e sociedade, bem como às possibilidades de uso destes recursos.

O primeiro elemento diz respeito à posse ou controle de recursos materiais ou simbólicos que permitem aos diversos atores se desenvolver em sociedade. O segundo se refere às estruturas de oportunidades que proveem (sic) do mercado, do Estado e da sociedade. Elas se vinculam em níveis de bem-estar, aos quais se pode ascender em um determinado tempo e território, podendo propiciar o uso mais eficiente dos recursos ou prover de novos ativos ou ainda recuperar aqueles esgotados. Por fim, o terceiro elemento refere-se a estratégias quanto ao uso que esses atores fazem de seu conjunto de ativos com vistas a fazer frente às mudanças estruturais de um dado contexto social. (ABRAMOVAY et al, 2002, p.30)

Complementando as reflexões já pontuadas, as vulnerabilidades sociais referenciadas pela política de Assistência Social no Brasil não se restringem às condições de pobreza, mas abarcam igualmente vitimizações, fragilidades e contingências que o cidadão, a cidadã e suas famílias enfrentam na trajetória de seu ciclo de vida, em decorrência de imposições sociais, econômicas e políticas. Semzezem e Alves (2013) demonstram que aspectos como o empobrecimento dos trabalhadores, o território em que vivem e a consequente dificuldade de sobrevivência material associada às questões de ordem cultural e relacional interferem drasticamente no modo de vida das famílias.

As autoras alertam que a condição de vulnerabilidade social implica no cidadão ou cidadã não ter potencialidades de resposta suficientes para enfrentar e superar as situações de risco naturais às suas vidas, o que impacta no seu grupo de pertencimento ou na sua comunidade. A insuficiência de respostas revela condições de precarização, vitimização e agressão a que são submetidos cotidianamente do ponto de vista social, econômico, cultural. Por outro lado, ao conseguirem estratégias de superação, eles demonstram capacidade ou resiliência, resistindo às situações desafiadoras à sua sobrevivência e/ou existência. Assim, os programas sociais ganham papel essencial ao garantir estratégias de proteção social a estes sujeitos de direitos. (SEMZEZEM; ALVES, 2013)

Carmo e Guizardi (2018, pp. 02-07) pontuam que vulnerabilidade social implica em considerar a ausência de renda e, igualmente, ponderar sobre as fragilidades de vínculos e “[...] desigualdade de acessos aos bens e serviços públicos”. As autoras em questão ressaltam que considerar vulnerabilidade social implica num olhar para além das condições individuais, mas, sobretudo, para as condições coletivas, pois a privação de renda ou dificuldade de acesso à renda interfere não só na autonomia, na liberdade e autorrespeito, mas também na proteção social e garantia de direitos.

Semzezen e Alves (2013) destacam que a vulnerabilidade pode se manifestar tanto pela ausência de recursos, como também quando o sujeito não dispõe de mecanismos de defesa para enfrentar situações de incertezas que são geradas nos ciclos de vida. Nessa linha de raciocínio, as autoras expõem que quanto à operacionalização do enfrentamento das situações de vulnerabilidade, referente ao público usuário da política de Assistência Social, é necessário criar indicadores que possam mensurar a vulnerabilidade social.

Ainda, Semzezen e Alves (2013) sugerem que, aliado ao levantamento dos indicadores, é fundamental um olhar atento ao território em que as famílias estão inseridas, pois os indicadores isoladamente, com ausência de análise da realidade social, ficam vazios de significado social, a julgar que: 
A mensuração da situação de vulnerabilidade social não parte somente das necessidades explicitadas pelos indivíduos ou famílias, mas também diz respeito aos recursos que esses sujeitos podem acessar no território vivido, tais como: serviços, programas, projetos e ações protetivas. Assim, a vulnerabilidade também está associada à insuficiência de uma rede de proteção que garanta às famílias o acesso aos direitos. (SEMZEZEN; ALVES, 2013, p.164).

Observa-se que a temática da vulnerabilidade social é complexa e exige a consideração de diversos elementos para que seja possível categorizar uma família/indivíduo como vulnerável. Além disto, é uma categoria que possibilita desenvolvimento de ações com vistas ao monitoramento de situações que possam agravá-la e investimentos em prevenção.

\section{A vulnerabilidade social no contexto do Programa Família Paranaense}

Antes de apresentar o Programa Família Paranaense, cabe sublinhar que a Política Nacional de Assistência Social foi aprovada no ano de 2004 e, em 2005, foi estabelecido o Sistema Único de Assistência Social (SUAS ${ }^{3}$ ), cuja finalidade é organizar as ações desenvolvidas no âmbito da política pública de Assistência Social em território nacional. Para tanto, os programas, projetos, benefícios e serviços no âmbito do SUAS são realizados sob a lógica do território mediante instalação de equipamento público estatal, pois se acredita que é possível perceber nesse espaço os processos de vulnerabilidade social que acometem as famílias.

As ações do SUAS são desenvolvidas procurando cumprir os seguintes objetivos: proteção social, defesa de direitos e vigilância social. E, nessa perspectiva, as categorias matricialidade sociofamiliar, território, equipamentos, rede socioassistencial e rede intersetorial configuram-se como elementos norteadores da operacionalização das ações do SUAS nos municípios brasileiros. Nesse sentido, Estados e Municípios tiveram que reorganizar suas ações no contexto da Assistência Social, procurando atender aos requisitos constantes nas normativas do SUAS.

No Paraná ocorreu a estruturação e a execução da Política de Assistência Social, sob a lógica do SUAS, com vistas ao enfrentamento das condições de pobreza e de vulnerabilidade social e, neste contexto, foi criado o Programa Família Paranaense, na gestão do governador Beto Richa (2011-2018) no ano de 2012. Atualmente, na gestão do governador Ratinho Jr. (2019-2022), é coordenado pela Secretaria de Estado da Justiça, Família e Trabalho (SEJUF) e conta com ações de aproximadamente 19 secretarias e empresas estaduais. Cabe esclarecer que o Programa Família Paranaense é a principal estratégia do governo do Estado para promoção da proteção social às famílias em situação de vulnerabilidade social. Para tanto, propõe ações planejadas e de caráter intersetorial, objetivando consolidar uma rede integrada de proteção às famílias. (PARANÁ, 2020). No quadro 01, é possível encontrar os benefícios que estão contemplados no interior do Programa Família Paranaense:

\footnotetext{
${ }^{3}$ Sobre O SUAS ver o livro: "SOUZA, C.G. Sistema Único de Assistência Social: a proteção e o atendimento à família. 1. ed. Ponta Grossa: Editora UEPG, 2018. 188p”.
} 
Quadro 01 - Benefícios Programa Família Paranaense

\begin{tabular}{|l|l|}
\hline Programa & Objetivos \\
\hline Renda Família Paranaense & $\begin{array}{l}\text { Consiste na transferência de renda direta às famílias que estão em } \\
\text { situação de vulnerabilidade social, estejam recebendo Bolsa Família } \\
\text { e que possuam renda familiar per capita superior a } \$ \text { \$ } 85,00 \text { e } \\
\text { inferior a } \$ \$ 95,00 .\end{array}$ \\
\hline Renda Agricultor Familiar & $\begin{array}{l}\text { Criado em 2015, o programa transfere um valor fixo às famílias da } \\
\text { área rural que estão em situação de vulnerabilidade social. }\end{array}$ \\
\hline Programa Luz Fraterna & $\begin{array}{l}\text { O Luz Fraterna isenta as famílias beneficiadas pela Tarifa Social } \\
\text { do pagamento da fatura de energia elétrica e que tem consumo de } \\
\text { energia mensal igual ou inferior a 120 kWh. }\end{array}$ \\
\hline Paraná Juro Zero & $\begin{array}{l}\text { O Paraná Juro Zero é uma linha de financiamento ofertada pela } \\
\text { Fomento Paraná em parceria com a SEJUF, por meio do programa } \\
\text { Banco do Empreendedor. A linha permite o acesso ao microcrédito } \\
\text { produtivo para famílias em situação de vulnerabilidade social } \\
\text { incluídas no Programa Família Paranaense. }\end{array}$ \\
\hline Caixa d'Água Família Paranaense & $\begin{array}{l}\text { O projeto Caixa d’Água Família Paranaense é uma ação da SEJUF e } \\
\text { da Companhia de Saneamento do Paraná (Sanepar), desenvolvida } \\
\text { em parceria com os municípios participantes do Programa Família } \\
\text { Paranaense. Realiza a disponibilização de } 1 \text { caixa d'água e } 1 \text { kit de } \\
\text { instalação às famílias em situação de vulnerabilidade social que } \\
\text { não possuem caixa d'água no domicílio. Estas famílias recebem } \\
\text { capacitação para instalação adequada e o subsídio financeiro de R\$ } \\
1.000,00 \text { (mil reais) para viabilização da instalação. }\end{array}$ \\
\hline
\end{tabular}

Fonte: (PARANÁ, 2020)

No que se refere ao arranjo da gestão do Programa, tem-se a seguinte configuração: A Unidade Gestora Estadual é responsável pela coordenação e articulação do Programa junto aos municípios; o Comitê Regional é responsável por realizar a assessoria e contato com municípios da região em que fica localizada a sede do Escritório Regional (ER) da SEJUF. Em âmbito municipal deve ser implantado e formalizado por ato administrativo do executivo um Comitê Municipal, que será composto de forma intersetorial; no que lhe concerne, o Comitê Local deverá ser composto por membros representantes das políticas públicas presentes nos territórios onde as famílias atendidas encontram-se. (PARANÁ, 2020).

No que se refere ao tempo, a proposta de acompanhamento das famílias inseridas no Programa Família Paranaense é de dois anos. Nesse período, o Plano de Ação é fundamental, tendo em vista que nele deve constar todas as necessidades das famílias, bem como as frentes de trabalho a serem realizadas com estas. Nesse momento, elencam-se as responsabilidades da rede de proteção social municipal, na qual não apenas a assistência social deve desenvolver suas ações, mas, sobretudo, a saúde, educação, habitação, agricultura e trabalho cumprem papel de relevância. (PARANÁ, 2019).

Para medir o grau de vulnerabilidade social, o Programa adota o percentil 75\% do Índice de Vulnerabilidades das Famílias do Paraná (IVF-PR). O IVF-PR visa contribuir no processo de caracterização e diagnóstico das famílias, mediante adoção de variáveis que evidenciem certas dimensões do contexto de vida delas, em que seja possível identificar situações de vulnerabilidade social e localizar o território em que as famílias se encontram. (NAZARENO et al, 2012). 
Acerca das dimensões, cabe salientar que o IVF-PR é representado por 19 indicadores, que são distribuídos em quatro dimensões, as quais estão explicitadas no quadro 02.

Quadro 02 - Dimensões e Indicadores do IVF-PR

\begin{tabular}{|l|l|}
\hline Dimensão & Indicadores \\
\hline Adequação do domicílio & $\begin{array}{l}5 \text { indicadores componentes: Espécie de Domicílio; Densidade por } \\
\text { Dormitório; Material de construção do domicílio; Água encanada e } \\
\text { Esgotamento Sanitário. } \\
\text { Pontuação máxima: } 12\end{array}$ \\
\hline Perfil e composição familiar & $\begin{array}{l}\text { 9 indicadores componentes: Responsabilidade pela família; Razão entre } \\
\text { crianças e adolescentes, e adultos; Presença de trabalho infantil na família; } \\
\text { Presença de crianças e adolescentes internados; Presença de adultos } \\
\text { internados; Presença de idosos internados; Presença de pessoas com } \\
\text { deficiência na família; Idosos em condição de agregado e Analfabetismo do } \\
\text { chefe de família. } \\
\text { Pontuação máxima: 20 }\end{array}$ \\
\hline Acesso ao trabalho e renda & $\begin{array}{l}\text { 2 indicadores componentes: Trabalho dos Adultos e Soma de todos os } \\
\text { rendimentos mensais, exceto de programas de transferência de renda, de } \\
\text { todas as pessoas da família dividida pelo número de pessoas da família na } \\
\text { data da entrevista. } \\
\text { Pontuação máxima: 13 }\end{array}$ \\
\hline Condiçães de escolaridade & $\begin{array}{l}3 \text { indicadores componentes: Crianças e adolescentes fora da escola; } \\
\text { Defasagem idade/série e Jovens e adultos sem ensino fundamental. } \\
\text { Pontuação máxima: } 8\end{array}$ \\
\hline
\end{tabular}

Fonte: (NAZARENO et al, 2012).

Nazareno et al (2012) explicam que a necessidade de construção do IVF-PR reside no fato de constituição de parâmetros para estabelecer prioridades em relação ao atendimento de famílias que se encontram em condições de vulnerabilidade social, buscando aprimorar o processo operacional das equipes que executam a política de assistência social nos municípios.

Feitas essas considerações sobre o IVF-PR, serão apresentados os índices do município de Ponta Grossa, com destaque para as famílias classificadas na categoria "alta vulnerabilidade social", bem como serão evidenciadas as ações e planejamento de ações desenhadas para as famílias incluídas no Programa, tendo o IVF-PR como indicador.

\section{A situação de vulnerabilidade social das famílias participantes do programa no Município de Ponta Grossa/PR.}

Primeiramente, é oportuno salientar que se elencou o município de Ponta Grossa-PR para demonstrar a relevância do IVF-PR enquanto estratégia para acesso do usuário ao Programa Família Paranaense e seus benefícios. Salienta-se que o município constitui-se em sede do Escritório Regional (ER) da SEJUF (Secretaria de Estado da Justiça, Família e Trabalho), onde se encontram 18 municípios localizados em sua área de abrangência. Destes, Ponta Grossa é o município de maior porte. 
Ponta Grossa (Figura 01) é um município localizado no Estado do Paraná, considerado importante entroncamento rodoferroviário, encontra-se a $117 \mathrm{~km}$ de distância da capital Curitiba e sua área territorial é de 2.042,673 km².

Figura 01 - Localização Ponta Grossa no Estado do Paraná



Fonte: (IPARDES, 2020)

De acordo com os dados do IBGE 2019, o município de Ponta Grossa tem 351.736 habitantes. Suas principais atividades econômicas estão concentradas na indústria, comércio, pecuária e agricultura, por sua vez, o turismo consiste em setor considerado em desenvolvimento. (IPARDES, 2020).

Quanto ao Índice de Desenvolvimento Humano Municipal (IDHM), observado no gráfico 01, os dados do IBGE de 2010 indicam que Ponta Grossa encontra-se na posição 13a no contexto do Paraná com índice de 0,763. (IPARDES, 2020).

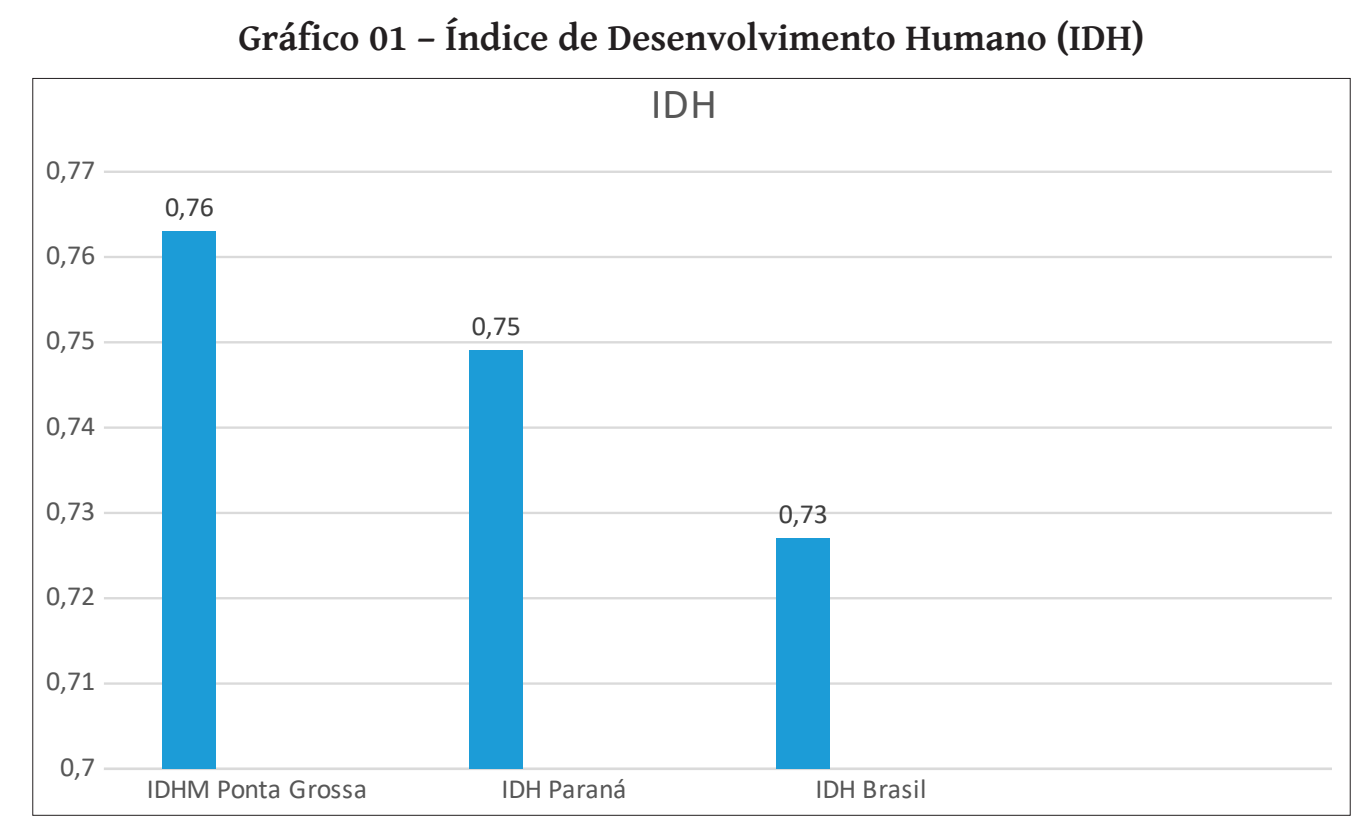

Fonte: (ATLAS BRASIL, 2020).

O valor do IDH pode variar entre 0 (zero) e 1 (um), quanto mais próximo do 1 (um), maior é o desenvolvimento humano, sinalizando que há, em processo, um avanço em três dimensões 
básicas do desenvolvimento humano: renda, educação e saúde. Os índices do IDH em Ponta Grossa, Paraná e Brasil são considerados altos, visto que para ser classificado nessa categoria a faixa de desenvolvimento humano tem que estar entre 0,700 e 0,799. (ATLAS BRASIL, 2020).

A Política Nacional de Assistência Social classifica os municípios por porte ${ }^{4}$, em que Ponta Grossa enquadra-se como município de grande porte, cuja população encontra-se entre 101.000 a 900.000 habitantes. No que tange à gestão do SUAS, desde 2005 Ponta Grossa é habilitada na gestão plena, o que significa que o município tem condições de gerir totalmente as ações na área da política pública de assistência social. (PONTA GROSSA, 2020).

O município dispõe de uma rede socioassistencial com 10 CRAS, dois CREAS e um Centro POP que atende a população em situação de rua, além de contar com as entidades não governamentais que compõem a rede e executam serviços, programas e projetos para atender as famílias em situação de risco e vulnerabilidade social. (PONTA GROSSA, 2020).

Ademais, no que tange às famílias em situação de vulnerabilidade social, o município atende famílias que também estão incluídas no Programa Família Paranaense. Salienta-se que em relação às modalidades de adesão do município, o Programa Família Paranaense está organizado em: municípios prioritários, adesão espontânea e Atenção às Famílias dos Adolescentes Internados por Medida Socioeducativa (AFAI) e Renda Família Paranaense.

No Paraná, há um total de 399 municípios, dos quais 156 são considerados prioritários, tendo em vista o valor do Índice IPARDES de Desempenho Municipal (IPDM), pelo percentual de extrema pobreza e pelo IVF-PR. (PARANÁ, 2017).

Já na modalidade adesão espontânea, encontram-se os demais municípios paranaenses (243) que aderem ao programa e passam a realizar o acompanhamento individualizado às famílias. Esses municípios devem realizar o acompanhamento sistemático das famílias em situação de alta vulnerabilidade social, com oferta de ações e serviços intersetoriais. (PARANÁ, 2017).

Destaca-se que Ponta Grossa enquadra-se na modalidade de adesão espontânea e AFAI. De acordo com os dados indicados no quadro 03, Ponta Grossa tem 9.368 famílias em situação de alta vulnerabilidade social conforme IVF-PR (percentil menor que 75\%).

Quadro 03 - Ponta Grossa famílias em vulnerabilidade social

\begin{tabular}{|l|l|}
\hline \multicolumn{2}{|c|}{ Ponta Grossa } \\
\hline Famílias cadastradas no CadÚnico & 37.477 \\
\hline Famílias em alta vulnerabilidade social & 9.368 \\
\hline Famílias em alta vulnerabilidade social com transferência de renda federal & 9.350 \\
\hline Famílias em alta vulnerabilidade social com renda família paranaense & 1.119 \\
\hline $\begin{array}{l}\text { Famílias em alta vulnerabilidade social com transferência de renda federal e renda família } \\
\text { paranaense }\end{array}$ & 1.110 \\
\hline $\begin{array}{l}\text { Famílias em alta vulnerabilidade social e incluídas no sistema de acompanhamento familiar } \\
\text { intersetorial }\end{array}$ & 60 \\
\hline $\begin{array}{l}\text { Famílias em alta vulnerabilidade social com transferência de renda federal e renda família } \\
\text { paranaense e incluídas no sistema de acompanhamento familiar intersetorial }\end{array}$ & 19 \\
\hline
\end{tabular}

Fonte: (PARANÁ, 2020)

\footnotetext{
${ }^{4}$ Para maiores informações sobre o porte dos municípios ver: BRASIL, POLÍTICA NACIONAL DE ASSISTÊNCIA SOCIAL/ Norma Operacional Básica - NOB/SUAS. Brasília: Ministério do Desenvolvimento Social e Combate à Fome/Secretaria Nacional de Assistência Social, 2005, p. 84.
} 
Observa-se no quadro 03 que 99,8\%, ou seja, quase todas as famílias em alta vulnerabilidade social, recebem transferência de renda do governo federal. Por sua vez, 11,94\% do total de famílias em alta vulnerabilidade social recebem ambos os benefícios: federal e estadual.

Cada família incluída possui um diagnóstico individual que busca indicar aos técnicos e gestores quais as maiores dificuldades vivenciadas em seu cotidiano. As 60 famílias e as 19 indicadas no quadro 03 possuem diagnóstico finalizado, ou seja, isso significa que já foi construído um retrato social delas, com a finalidade de identificar suas vulnerabilidades e potencialidades, aspecto que contribui para a construção do plano de ação.

É oportuno ressaltar que o Diagnóstico é composto pelo IVF-PR e pelos Aspectos para Investigação, que consistem em informações que auxiliam na complementação dos dados do Cadastro Único, formado por cerca de 70 perguntas divididas em oito categorias (PARANÁ, 2018). Sendo estas: violência e direitos humanos, direitos de crianças e adolescentes, documentação civil básica, domicílio, saúde, trabalho e renda, segurança alimentar e vínculos comunitários e familiares, (PARANÁ, 2018).

Ao ser alimentado com as informações do IVF-PR e dos aspectos para investigação, o diagnóstico auxilia o comitê local no estabelecimento de estratégias que serão desenvolvidas para atender as demandas familiares com vistas ao enfrentamento da vulnerabilidade social. Tais estratégias devem ser delimitadas no plano de ação.

Para coletar os dados, é necessário que os técnicos que compõem o comitê local realizem visitas domiciliares para agregar o maior número possível de informações sobre as condições da família. Além disso, podem ser realizados atendimentos individualizados com os membros da família.

Enfatiza-se que o plano de ação não é um instrumento que deve ficar restrito a apenas uma área de atuação, como a política municipal de saúde, por exemplo, pois a lógica é que a rede intersetorial cumpra com suas atribuições em relação ao plano de ação e à família. Isto é, essa dinâmica exige a participação e reunião regular do comitê local.

O Plano de Ação é um instrumento que norteia o acompanhamento a ser realizado com a família. A partir da análise aprofundada de cada caso, compreende a singularidade da família e organiza as ações e atividades a serem desenvolvidas com cada membro familiar, identifica os membros do Comitê Local e os parceiros responsáveis por cada ação e delimita um prazo para que os resultados sejam alcançados. (PARANÁ, 2018, p. 41).

Na medida em que é construído, O plano de ação terá uma primeira versão, que pode e deve ser alterada à medida que a realidade familiar passe por alterações, o que denota constante monitoramento das ações planejadas. O plano de ações deve ser estabelecido a partir dos seguintes eixos, conforme explicitado na figura 02. 


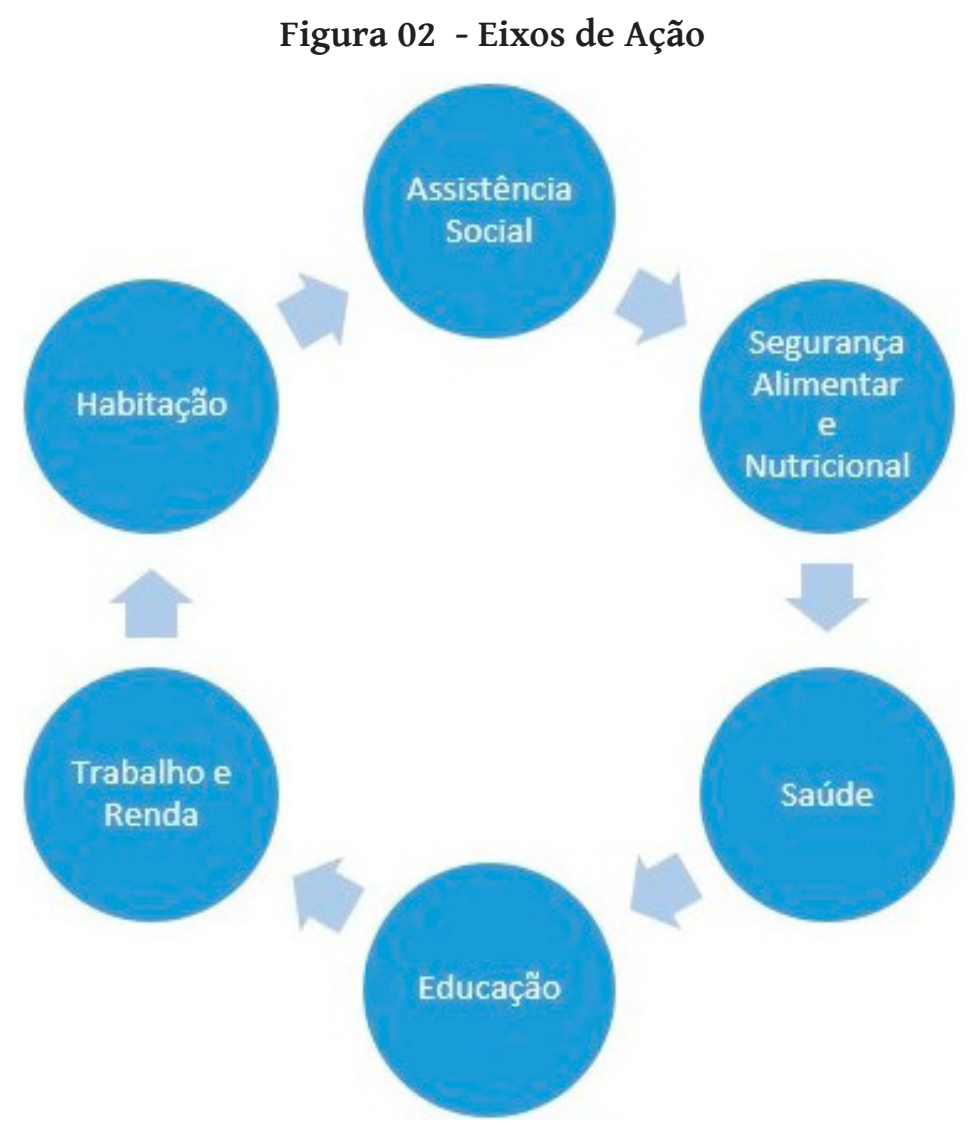

Fonte: Paraná (2018)

Os eixos definidos no plano de ação correspondem a um norte para serem elencadas as prioridades de forma setorializada, deve-se destacar que, geralmente, as políticas setoriais possuem serviços e atendimentos tipificados no que se refere ao atendimento de famílias em situação de vulnerabilidade social. Assim, o plano deve contemplar tais ações e ainda pode e deve conter ações específicas para o público-alvo do Programa Família Paranaense, como inserção no Renda Agricultor Familiar, por exemplo. (PARANÁ, 2018).

Em relação às 60 famílias indicadas no quadro 03, que se encontram em alta vulnerabilidade social e estão incluídas no sistema de acompanhamento familiar intersetorial, foi desenvolvido um plano de ações com elas, sendo que as intervenções se centraram nos seguintes eixos demonstrados no gráfico 03: 
Gráfico 03 - Quantitativo de ações estabelecidas por eixo

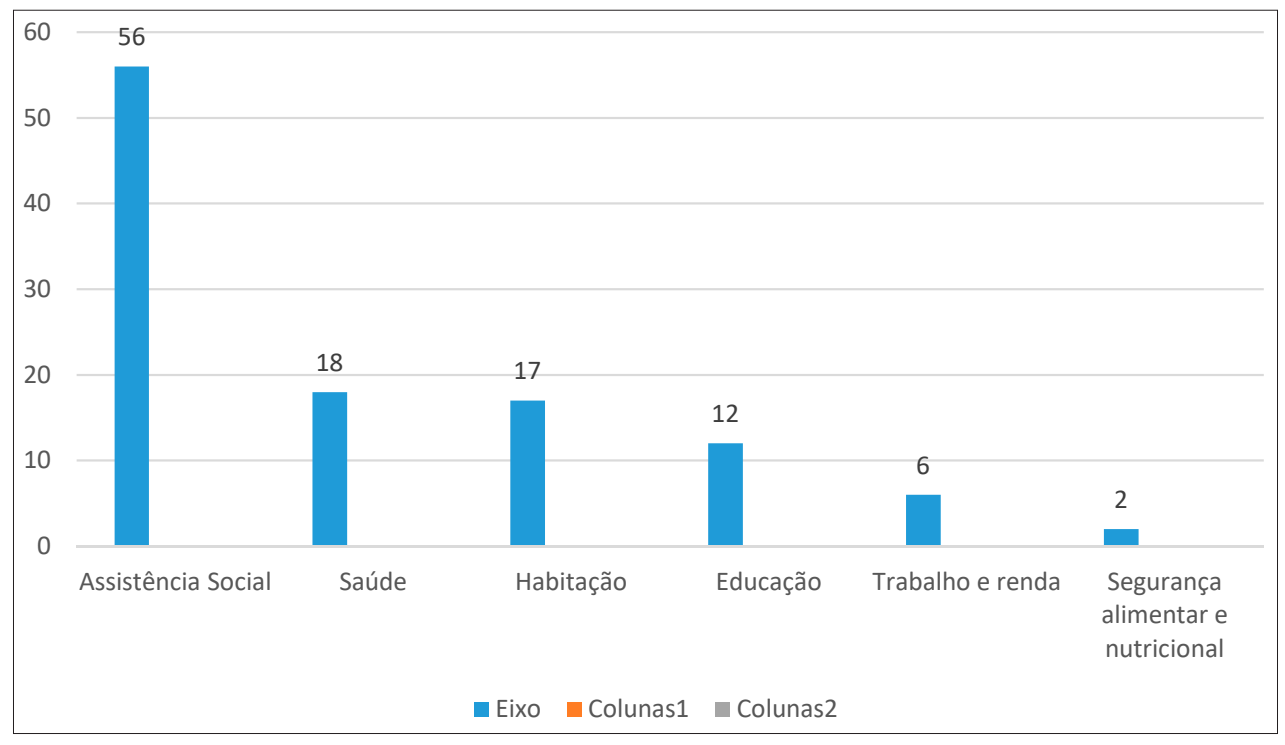

Fonte: (PARANÁ, 2020)

Os números correspondem ao quantitativo de ações setoriais que foram elencadas em cada plano de ação de acompanhamento familiar. É importante destacar que em uma mesma família, por exemplo, podem ser estabelecidas mais de uma ação no eixo da Assistência Social, visto que as ações são planejadas considerando cada membro familiar, aspecto que justifica a razão de a assistência social ser o eixo com maior número de ações propostas para intervenção no processo de acompanhamento das famílias.

Percebe-se assim a alta demanda de atendimento centrado na Assistência Social e, ao analisar o plano de ações, as mesmas; no eixo da Assistência Social. Em sua grande maioria, correspondem à inserção no Serviço de Proteção e Atendimento Integral à Família (PAIF), no Serviço de Convivência e Fortalecimento de Vínculos (SCFV), encaminhamentos para acesso à documentação civil básica, acesso a benefícios socioassistenciais, como benefícios eventuais e Benefício de Prestação Continuada (BPC).

Em relação à centralidade da política de Assistência Social, Mota (2010, p.144) apresenta um importante argumento:

Ao absorver as demandas derivadas do agravamento das condições de vida e trabalho da população brasileira através de políticas compensatórias, como é o caso da Assistência Social, o Estado brasileiro define sua principal estratégia de enfrentamento da "questão social". Nestes termos, a Assistência Social passa a assumir, para uma parcela significativa da população, a tarefa de ser a política de proteção social e não parte da política de proteção social.

A autora reforça ainda que na atual conjuntura de precarização das condições e relações de trabalho, a Assistência Social acaba por oferecer serviços e benefícios que tem o potencial de “[...] suprir necessidades que seriam do âmbito de outras políticas [...]" (MOTA, 2010, p. 144). Isto se deve à condição de extrema vulnerabilidade em que vivem as famílias pobres.

No entanto, a articulação com as demais políticas é necessária para a busca de resposta às demandas destas famílias. Assim, observa-se que as demandas no âmbito da saúde, habitação e educação são expressivas. Na saúde, as ações centram-se no agendamento de consultas 
médicas/odontológicas, efetivação das vacinas conforme calendário do Ministério da Saúde, encaminhamentos para serviços de referência em dependência química e serviços da Rede de Atenção Psicossocial.

No eixo da habitação, as ações concentram-se em encaminhamentos e orientações para cadastro em ações do órgão municipal de Habitação, reassentamento de famílias localizadas em área de risco, regularização fundiária e orientações quanto aos programas de subsídio para energia, como por exemplo Luz Fraterna.

Já no eixo da educação, as ações foram planejadas na de realização de matrículas na educação infantil, educação fundamental e na Educação para Jovens e Adultos (EJA).

No que lhe concerne, no eixo do trabalho, as ações foram planejadas em torno da inserção em cursos de qualificação profissional, bem como encaminhamentos para inserção no mercado de trabalho formal, com contrato de trabalho e inclusão em vagas para estágios ou programas de aprendizagem.

No eixo da segurança alimentar e nutricional as ações planejadas centraram-se na inclusão de crianças no Programa Leite das Crianças e inclusão das famílias como consumidora de segurança alimentar/aquisição de alimentos.

Após a construção do plano de ações, o qual deve ser elaborado com consentimento e participação da família, há um fluxo de ações a ser seguido. O fluxo serve como uma estratégia para organização do comitê local no processo de acompanhamento familiar. "Trata-se de um caminho de possibilidades que estabelece uma lógica de continuidade, envolvendo a necessidade de organização, planejamento e estratégia”. (PARANÁ, 2018, p. 21). Neste fluxo (figura 03), a família pode passar pelos seguintes processos:

Figura 03 - Fluxo de ações para acompanhamento da família



Fonte: (PARANÁ, 2018, p.43) 
Percebe-se que o Comitê Local tem uma grande responsabilidade na execução do Programa Família Paranaense. Dessa forma, é necessário o desenvolvimento de um trabalho articulado em tempo integral, com vistas ao acompanhamento e atendimento das demandas das famílias.

Quanto ao acompanhamento de famílias que se encontram em situação de alta vulnerabilidade social, pontua-se que as demandas apresentadas exigem um longo prazo para serem atendidas, justamente por se tratar de demandas complexas e que exigem o comprometimento da rede de proteção social. Logo, destaca-se a necessidade de que as intervenções sejam realizadas de fato e continuamente. (SOUZA, 2018).

Igualmente, salienta-se que o processo de acompanhamento familiar requer trabalho qualificado, com domínio técnico e ético. 0 acompanhamento implica em conhecimento do território, das relações que a família apresenta com a comunidade, se é uma relação frágil ou se apresenta vínculos. O conhecimento do território exige a construção de diagnóstico para perceber se ele revela possibilidades ou ausência de proteção social. (SOUZA, 2018).

No que se refere à gestão das políticas, em muitas realidades municipais, os componentes do Comitê Local respondem por outras atribuições em seus respectivos espaços de trabalho. Isto é, exercem funções que não são especificamente relacionadas à execução do Programa em tempo integral.

Pondera-se que o Programa fornece uma proposta e metodologia ricas no que concerne ao plano de ação e processo de acompanhamento das famílias. O Programa, igualmente, disponibiliza um sistema com ferramentas que favorecem o monitoramento das ações inseridas no Plano, por ser possível comparar ações realizadas pela rede e observar qual política/serviço não cumpriu a meta estabelecida para atendimento da demanda da família. Contudo, observa-se que o grande desafio do programa e da rede de proteção articulada para atendimento das famílias é a questão de articular ações entre as diferentes políticas envolvidas de forma a garantir superação da condição de vulnerabilidade social em que as famílias vivem. Tal questão leva às reflexões sobre as possibilidades e limites da Política de Assistência Social e programas sociais a ela relacionados.

As demandas dos usuários das políticas públicas não são fragmentadas, suas demandas são complexas e heterogêneas e retratam que "[...] as condições de pobreza e vulnerabilidade social afetam múltiplas dimensões da vida e de sobrevivência dos cidadãos e de suas famílias." (YAZBEK, 2014, p. 97). A reflexão da autora citada reforça que o sistema protetivo destinado à família usuária de programas sociais deve ocorrer de forma integrada e articulada, o que exige um sistema de gestão que fortaleça o princípio da intersetorialidade prevista na configuração da política de Assistência Social.

A autora em tela argumenta que a intersetorialidade consiste numa dinâmica que implica articulação e ação conjunta e colaborativa das políticas públicas, cujo foco seja a proteção social das famílias. Portanto, tem como suposto estabelecimento de um projeto comum entre as políticas públicas envolvidas, sob a égide de que esforços devem ser somados com vistas ao enfrentamento das situações de desproteção social identificadas. Para tanto, é urgente enfrentar a lógica de ações fragmentadas de atenção às necessidades e demandas sociais da população.

Ações em rede e que materializam o princípio de intersetorialidade potencializam as possibilidades de acesso das famílias aos seus direitos sociais. É inegável que as fragilidades do sistema de proteção social e as transformações sociais, econômicas e políticas contemporâneas agravam as condições de vulnerabilidade social das famílias, acarretando sobrecarga às famílias pobres em garantir meios de sobrevivência material e na busca de proteger minimamente seus membros. Tais famílias não têm acesso continuado à educação, saúde, segurança e ao trabalho 
em suas trajetórias. Neste sentido, políticas públicas articuladas facilitam o atendimento concreto às suas necessidades de forma a promover acesso à renda, a bens e serviços que garantam proteção social. (ALMEIDA, et al, 2016)

Assim, os indicadores sociais ganham papel estratégico, pois são relevantes para orientar a formulação e implementação de programas sociais e definir processos de avaliação de políticas públicas. Assim como contribuem para a elaboração de diagnósticos sociais, monitoramento de ações e avaliações que impactem em resultados e, efetivamente, sejam significativos para a superação da condição de vulnerabilidade as famílias. (ALMEIDA, et al, 2016)

As situações de vulnerabilidade social vivenciadas pelas famílias atendidas pelo Programa Família Paranaense estão diretamente ligadas à miséria estrutural. Realidade que não difere das demais famílias pobres brasileiras e, conforme alertam Cronemberger e Teixeira (2013, p. 21):

Esse estado de privação de direitos atinge todos os membros da família de forma profunda: incita e precipita a ida das crianças para a rua e, na maioria das vezes, o abandono da escola, a fim de ajudar no orçamento familiar, comprometendo, de forma significativa, o desenvolvimento das crianças; provoca o abandono dos idosos, dentre outras mazelas, o que favorece o enfraquecimento das relações, sejam afetivas, sociais, econômicas ou culturais.

Portanto, programas como o pautado neste artigo acabam se constituindo como estratégia fundamental no combate à pobreza, às vulnerabilidades, garantindo um mínimo de oportunidade de acesso a alguns serviços e benefícios estipulados no âmbito da Política Nacional de Assistência Social.

\section{Conclusão}

Silva, Yazbek e Giovanni (2004), ao analisar a política social brasileira, demonstram que o contexto da proteção social brasileira é insuficiente para o enfrentamento e superação das desigualdades sociais e consequente agravamento das condições de vulnerabilidade social a que são submetidas as famílias. O crescente processo de precarização das relações de trabalho e de desproteção social materializado nas condições de vida da população obriga as famílias a buscar programas de natureza compensatória, por um lado e por outro tais programas se configuram como única alternativa de rompimento de círculos viciosos de reprodução da pobreza.

Diante desse contexto, os indicadores são potenciais instrumentos de monitoramento e avaliação das políticas sociais e, especialmente, podem apontar estratégias concretas de enfrentamento das situações de vulnerabilidade, referente ao público usuário da política de assistência social para os municípios.

O artigo evidencia que o enfrentamento de situações de pobreza e vulnerabilidade social exige ações articuladas e organizadas. Dessa forma, tem-se como ponto de partida a intersetorialidade, pois as famílias/indivíduos que se encontram em vulnerabilidade apresentam um universo heterogêneo de demandas, as quais não podem ser atendidas a partir da ação de apenas uma política pública, como a assistência social.

A política pública de Assistência Social pode ser a porta de entrada dessas demandas por sua inserção nos territórios de vulnerabilidade. Sobretudo, devido à perspectiva de acolhida dessas demandas pela equipe dos(as) trabalhadores(as) dos equipamentos da assistência social. 
No entanto, o rol de indicadores apresentados nesse artigo elucida o quão complexas são as demandas que as famílias/indivíduos que estão em vulnerabilidade social apresentam. Assim, é necessário o estabelecimento de uma rede socioassistencial e intersetorial para atendimento dessas demandas.

Outro ponto que merece destaque é a pandemia gerada pela Covid-19, momento que marca não apenas o Paraná, mas o Brasil na totalidade e trouxe impactos socioeconômicos sobre a população, aumentando o número de famílias/indivíduos em situação de vulnerabilidade social. Aliado a esse fenômeno, tem-se um recorrente processo de cortes nos recursos destinados às políticas sociais, aspecto que incide de forma contundente na materialização dos programas, projetos, serviços e benefícios. Destarte, tal aspecto deve ser ponderado, haja vista que repercute na capacidade, por exemplo, do comitê local executar o Plano de Ação e o processo de acompanhamento das famílias que são inseridas no Programa Família Paranaense.

Assim, por um lado, apresenta-se uma proposta de estabelecimento de um Plano de Ação, com acompanhamento sistemático das famílias por um conjunto de atores que pertencem à rede intersetorial. Por outro lado, há corte de investimentos em recursos humanos e em estrutura, o que gera obstáculos para execução do acompanhamento familiar.

Portanto, observa-se que para execução do Plano de Ação e consequente acompanhamento das famílias em situação de vulnerabilidade social, há certos fatores que precisam ser ponderados. Dentre eles destacam-se: constituição de equipes profissionais qualificadas, vontade política e gestão que forneça subsídios suficientes para que a rede de proteção social local possa ser instrumentalizada para realizar o acompanhamento das famílias e, em dois anos, favorecer o desencadeamento de um processo que minimize situações de vulnerabilidade social.

Pautados tais desafios e o contexto de precarização das condições de vida dos usuários da Política de Assistência Social, enfatiza-se a relevância dos gestores e profissionais terem indicadores sociais como referência para diagnosticar, planejar e avaliar as ações de enfrentamento às vulnerabilidades sociais.

\section{Referências}

ABRAMOVAY, Miriam et al. Juventude, violência e vulnerabilidade social na América Latina: desafios para políticas públicas. Brasília: UNESCO, BID, 2002. Disponível em https://unesdoc.unesco. org/ark:/48223/pf0000127138. Acesso em 10 de Abr. de 2020.

ALMEIDA, C. M. de et al. Principais situações de vulnerabilidade social das famílias da microrregião de Ubá. Revista Brasileira de Economia Doméstica. Viçosa, MG. Oikos v. 27, n.1, p. 31-58, 2016. Disponível em https://www.locus.ufv.br/bitstream/handle/123456789/20234/artigo. pdf?sequence=1\&isAllowed=y . Acesso em 27 de Abr. de 2020.

ATLAS BRASIL. Atlas do Desenvolvimento Humano no Brasil. Disponível em http://www.atlasbrasil. org.br/2013/pt/perfil_uf/parana Acesso em 20 de Abr. de 2020.

CARMO, M.E.; GUIZARDI, F.L. O conceito de vulnerabilidade e seus sentidos para as políticas públicas de saúde e assistência social. In: Cad. Saúde Pública 2018; 34(3):e00101417. Disponível em http://www. scielo.br/pdf/csp/v34n3/1678-4464-csp-34-03-e00101417 Acesso em 19 de Jan. de 2020.

CRONEMBERGER, I. H. G. M.; TEIXEIRA, S. T. Famílias vulneráveis como expressão da questão social, à luz da política de assistência social. Revista Eletrônica informe econômico. Ano 1, n. 1, ago. 2013. 
Disponível em https://revistas.ufpi.br/index.php/economiaufpi/article/view/1267. Acesso em 27 de Abr. de 2020.

GABATZ, C. Reflexões sobre exclusão e vulnerabilidade social no brasil contemporâneo. Sociedade em Debate, 21(1): 33-49, 2015. Disponível em http://revistas.ucpel.edu.br/index.php/rsd/article/ view/1004 Acesso em 17 de Abr. de 2020.

GARBOIS, Júlia Arêas; SODRE, Francis; DALBELLO-ARAUJO, Maristela. Da noção de determinação social à de determinantes sociais da saúde. Saúde debate, Rio de Janeiro, v. 41, n. 112, p. 63-76, Mar. 2017. Disponível em http://www.scielo.br/scielo.php?script=sci_ arttext\&pid=S010311042017000100063\&lng=en\&nrm=iso Acesso em 01 Abr. 2021

IPARDES. CADERNO ESTATÍSTICO MUNICÍPIO DE PONTA GROSSA. Disponível em http://www. ipardes.gov.br/cadernos/MontaCadPdf1.php?Municipio=84000. Acesso em 12 de Abr. de 2020.

MONTEIRO, S. R. da R. P. O marco conceitual da vulnerabilidade social. Sociedade em Debate, RS: Pelotas, 17(2): 29-40, jul-dez./2011. Disponível em http://revistas.ucpel.edu.br/index.php/rsd/article/ view/695 Acesso em 17 de Abr. de 2020

MOTA, A. E. A centralidade da assistência social na Seguridade Social brasileira nos anos 2000. In MOTA, A. E.(org). 0 mito da Assistência Social: ensaios sobre Estado, política e Sociedade. $4^{\mathrm{a}}$ edição. São Paulo: Cortez Editora, 2010. 256p.

NAZARENO et al. Índice de Vulnerabilidade das Famílias Paranaenses: Mensuração a partir do Cadastro Único para Programas Sociais - CadÚnico. In: Instituto Paranaense de Desenvolvimento Econômico e Social (IPARDES). Nota Técnica. Curitiba: IPARDES; 2012.

PARANÁ. Manual de orientação: Instrumentos de compromisso, diagnóstico, planejamento e acompanhamento das famílias. Disponível em encurtador.com.br/hltX1 Acesso em 12 de Dez. de 2019.

PARANÁ. Programa Família Paranaense. Disponível em http://www.justica.pr.gov.br/Pagina/ Programa-Familia-Paranaense Acesso em 19 de Jan. de 2020.

PARANÁ. Índice de Aderência. Informe Técnico № 01. Curitiba. 2018. Disponível em http://www. justica.pr.gov.br/Pagina/Publicacoes-Familia-Paranaense Acesso em 19 de Jan. de 2020.

PARANÁ. Família Paranaense: Guia de orientação. Curitiba. 2017. Disponível em http://www. justica.pr.gov.br/sites/default/arquivos_restritos/files/migrados/File/divulgacao/Guia_de_ OrientacaoFPrev3.pdf. Acesso 24 de Abr. de 2020.

PONTA GROSSA. PMAS - Plano Municipal de Assistência Social Município de Ponta Grossa 2018-2021. Disponível em https://cmas.pontagrossa.pr.gov.br/wp-content/uploads/2019/02/PMAS-2018-2021aprovado-pelo-CMAS.pdf Acesso em 20 de Abr. de 2020.

SEMZEZEM, P.; ALVES, J. M. Vulnerabilidade Social, abordagem territorial e proteção na política de Assistência Social. Serviço Social em Revista, Londrina, v. 16, n.1, P. 143-166, Jul./Dez. 2013. Disponível em http://www.uel.br/revistas/uel/index.php/ssrevista/article/view/16115/14627em Acesso em 19 de Jan. de 2020.

SILVA, O. da S. e; YAZBEK, M. C.; GIOVANNI, G. di. A política social brasileira no século XXI: a prevalência dos programas de transferência de renda. São Paulo: Cortez Ed. 2004. 248p.

SILVEIRA, J, I. Sistema Único de Assistência Social: institucionalidade e práticas. BATTINI, Odária (org) SUAS: Sistema Único de Assistência Social em debate. São Paulo: Veras Editora; Curitiba/Pr: CIPEC, 2007. 190p. 
SOUZA, C.G. Sistema Único de Assistência Social: a proteção e o atendimento à família. $1^{\text {à }}$. ed. Ponta Grossa: Editora UEPG, 2018. 185p.

SPOSATI, Aldaíza. Modelo brasileiro de proteção social não contributiva: concepções fundantes. In: Concepção e gestão da proteção social não contributiva no Brasil. Brasília: Ministério do Desenvolvimento Social e Combate à Fome, UNESCO, 2009. Disponível em http://www.mds.gov.br/ webarquivos/publicacao/assistencia_social/Livros/concepcao_gestao_protecaosocial.pdf. Acesso em 25 de Abr. de 2020.

YAZBEK, M.C. Sistemas de Proteção Social, intersetorialidade e integração de políticas sociais. In MONNERATT, G.L.; ALMEIDA, N.L.T de; SOUZA, R.G. de. A intersetorialidade na agenda das políticas sociais. Campinas/SP: Papel Social, 2014. 286p. 